\title{
Challenges and Opportunities to Overcome The Impact Of COVID-19 Pandemic on Power Engineering Education
}

\author{
Ioana Opriș, Cristina Sorana Ionescu, Sorina Costinaș, \\ Daniela Elena Gogoașe Nistoran
}

\author{
University POLITEHNICA of Bucharest, Splaiul Independenței 313, Bucharest, Romania
}

\begin{abstract}
The overall objective of this paper is to propose a viable approach to quality Education in Power Engineering during the COVID-19 period. To this end, we base the study on our previous steps in implementing Augmented Reality technology for training future engineers in the field of energy. To cope with the present challenges brought by the COVID-19 pandemic, we analyzed the necessary paradigm shift to maintain the benefits of using Augmented Reality in teaching.
\end{abstract}

Keywords - Augmented Reality, Power Engineering, Education, COVID-19.

\section{Introduction}

The COVID-19 pandemic abruptly changed the way we interact, approach and deliver education. Suddenly, from face-to-face teaching, we had to move directly into the online environment.

Unprecedented COVID-19 pandemic forces engineering universities to reshape rapidly their teaching systems [1], [2]. Advances in digital technologies change the society, the life of people and the way companies work [3].

DOI: $10.18421 /$ TEM94-48

https://doi.org/10.18421/TEM94-48

Corresponding author: Ioana Opriș, University POLITEHNICA of Bucharest, Faculty of Power Engineering.

Email: ioana.opris@upb.ro

Received: 12 October 2020.

Revised: 10 November 2020.

Accepted: 18 November 2020.

Published: 27 November 2020.

(cc) BY-NC-ND (C) 2020 loana Opriș et al; published by UIKTEN. This work is licensed under the Creative Commons Attribution-NonCommercial-NoDerivs 4.0 License.

The article is published with Open Access at www.temjournal.com
In the context of compulsory social distance required both by measures to protect human health and to avoid the further spreading of the virus, the Augmented Reality (AR) technology proves to be a useful instrument to be preserved and enhanced, facilitating an immersive experience-that ties the virtual and physical environment [4].

AR technologies can be used in distance teaching, including emergency situations, as COVID-19 [5].

The main benefits of using AR technology for students were emphasized in several papers even before COVID-19 pandemic: a deeper understanding of subjects and greater commitment [6], [7]. Even a drawback concerning the interaction with the AR technology to integrate additional information which already exists [8], the advantages greatly exceed this disadvantage.

A physical virtual laboratory is described in [9]. [10] used AR with good results to implement real laboratory experiments in the field of materials science to enable students to carry out their experiments from home. [11] showed the advantages of using AR in anatomy education.

The use of a smartphone or a tablet is both a simple and a cheap way to see AR images [12]. Mobile applications have an even greater potential during this pandemic period [13].

In our prior studies, we explored and tested AR in education by adopting a step-by-step approach [14], [15].

This paper extends the previous work, discussing the usefulness of maintaining the benefits of AR in power engineering education under the online teaching imposed by COVID-19 pandemic restrictions.

\section{Findings of the Face-to-Face Implementation Stage of AR in Power Engineering Education}

Future specialists in power engineering are expected to know and easily handle the main concepts on power plants (regarding design, operation, maintenance and management), but also the functioning of the specific components or 
systems related to power plants [15]. Aiming at acquiring a holistic education, a high degree of interdisciplinarity is needed.

Due to the large dimensions of power plants and their high costs, most of the physical phenomena cannot be replicated in laboratories. Moreover, some situations (such as abnormal operation conditions and bad operation decisions) and their consequences may be too dangerous to be reproduced in a laboratory. Therefore, some pictures, videos and numerical simulations are used to show and explain such instances.

Within the University Politehnica of Bucharest, Romania, AR was introduced in three laboratories of the Power Engineering Faculty:

- Nonelectrical Parameters Measurement Laboratory (NePM) - within which measurement procedures and use of nonelectrical parameters are studied;

- River Hydro Laboratory (RH) - within which phenomena related to water flow in hydro power plants are studied;

- Electrical Part of Power plants and Substations Laboratory $(\mathrm{EPPpS})$ - within which a dynamic model of electric power system (medium voltage substation schemes) made on an industrial scale, is studied.

During the first step of implementation, students and teachers worked together to create augmentations. AR was introduced [14]:

- in course manuals and laboratory handbooks,

- in laboratory, to support practical experiments during the laboratory work.

Depending on the context within which they were used, AR visualizations focused on different tasks.

Within laboratories, augmentations appeared by pointing the smart phone or tablet on a specific place. Examples include: the inner of a Bourdon manometer (Fig. 1); guidelines for the laboratory work consisting in photos explanatory videos; web links to industrial manufacturing companies, provided by $\mathrm{QR}$ codes posted on equipment. Fig. 2 shows an example of using the QR code for medium-voltage switchgear ABB's UniGear ZS1 [16].

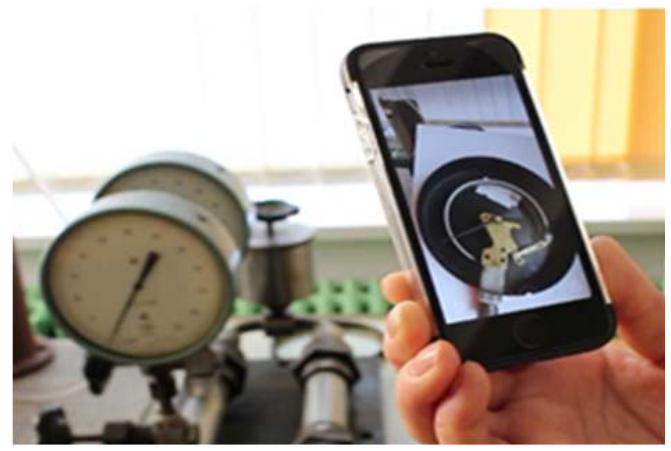

Figure 1. The use of AR in the laboratory; inside view of equipment (Bourdon manometer)
During the implementation stage it was found that AR triggers images that are easier to be recognized and focussed in a book than within the surroundings. Therefore, AR was introduced preferably in manuals and handbooks, to allow a user friendlier and complete explanation of the studied subjects.

Examples include power plants views (Fig. 3); insitu views of equipment (Fig.4).

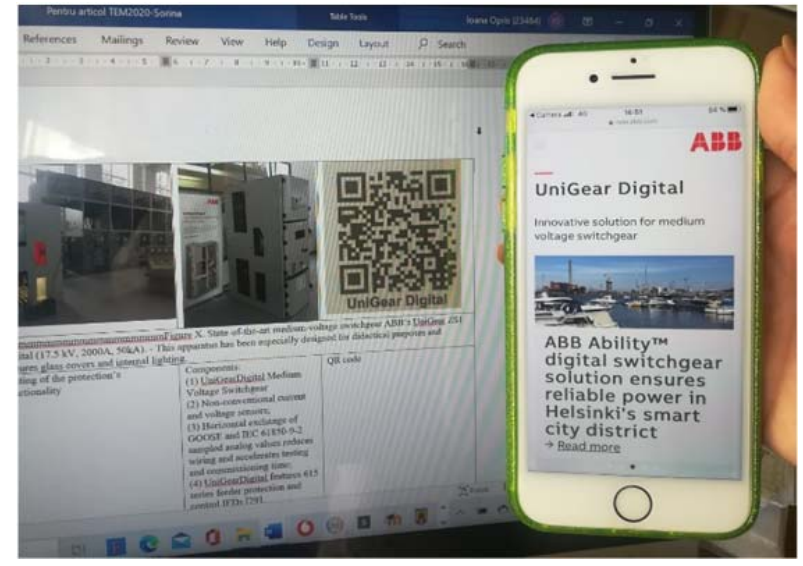

Figure 2. Web links to industrial manufacturing companies (medium-voltage switchgear)

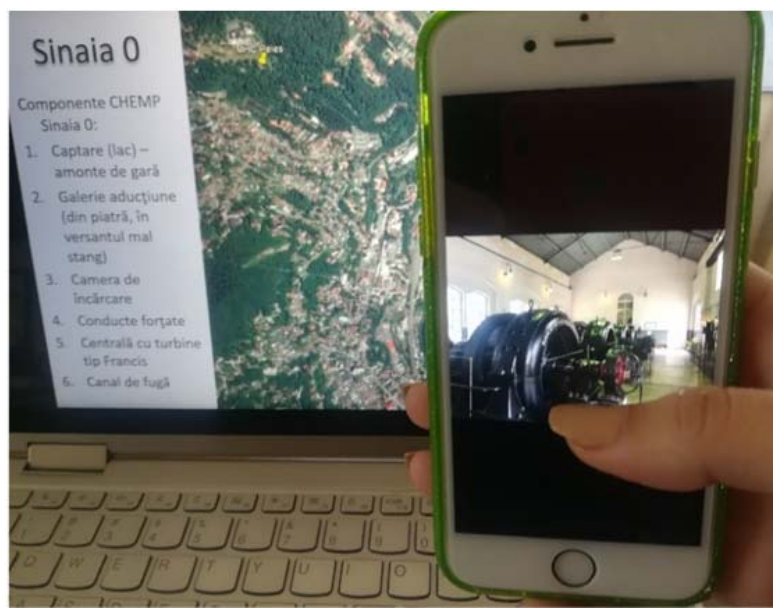

Figure 3. Power plant views $4 \times 250 \mathrm{~kW}$ hydro power plant on Prahova river, within Sinaia 0)

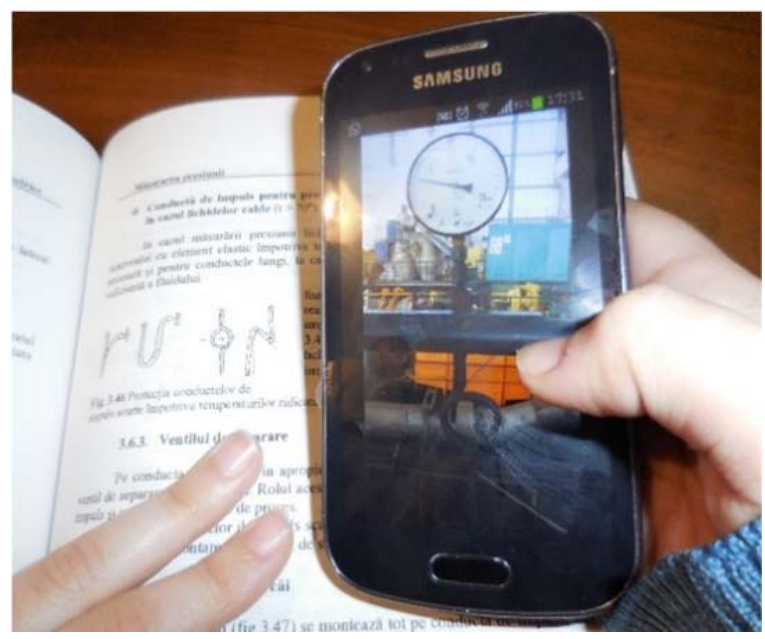

Figure 4. In-situ views of equipment (steam pressure measuring in a $50 \mathrm{MW}$ thermal power plant) 
For each lab experiment the guidelines within the handbook were supplemented with new images and video explanations (Fig. 5).

It's important to highlight that augmentation appears regardless the handbook is printed (Fig. 4) or displayed on a computer (Fig. 2).

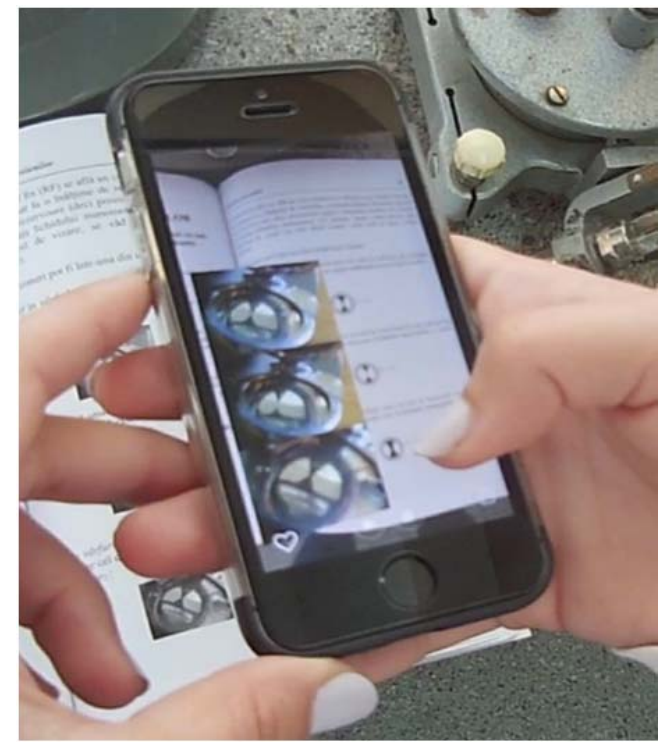

Figure 5. Guidelines within a handbook (pressure measurement with Askania micromanometer)

A major result of the first AR implementation stage [15] was that students were mostly excited when using the technology during the lab work. As well, students stated they had better learning experiences when viewing inner and in-situ images of equipment and processes. Thus, a tighter link between theory and practice was made, allowing a faster and deeper understanding and learning.

\section{COVID-19 Challenges for Implementation of $A R$ in Power Engineering Education}

The sharp change from face-to-face to online training triggered our need to fill this gap induced by the COVID-19 pandemic. In the fight with this challenge, the internet connection is the required utility to enable the use of teaching tools such as course management and communication platforms.

Within our university the tools we use are Moodle and Windows Teams.

The Moodle platform was mainly designed:

- to offer educators the means to create training materials for courses and practical applications, and to evaluate students,

- to provide students with online access to training materials, to enable them to have a good quality education, as well as to make exams,

- to provide both educators and students a communication environment e.g. through Chat and Forums.
The Windows Teams platform was mainly conceived:

- to provide a meeting room to allow teachers and students live communication (video, sound and chat)

- to upload teaching materials,

- to launch questionnaires (through Microsoft Forms).

The AR technology is the link between face-toface and online teaching. This link is particularly important in engineering education where practical training is of utmost concern. In this respect, AR is one of the actual bridges that can narrow the gap between online and face-to-face teaching (Fig. 6).

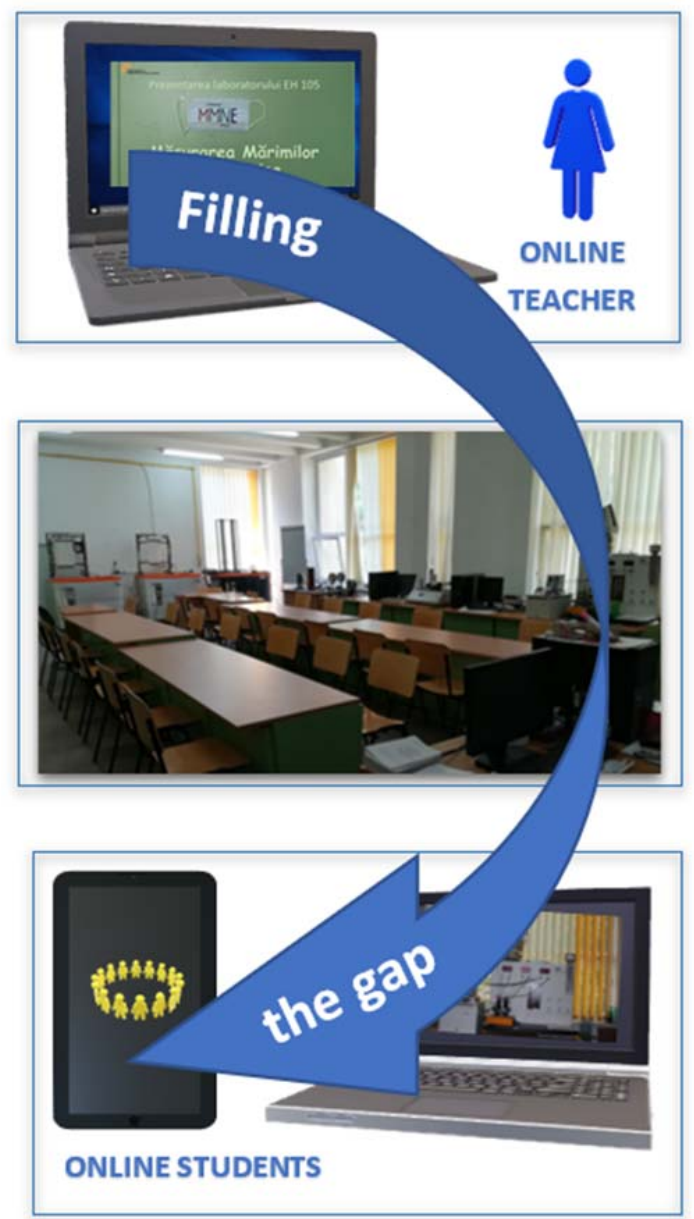

Figure 6. Filling the gap between face-to-face and online teaching

However, the online approach involves some necessary adjustments to using AR. The most obvious example is that restriction measures imposed by decision makers to avoid the spreading of COVID-19 prevent for some time the direct performance of experiments within laboratories. Therefore, the augmentations prepared to be used during real experiments become useless. Instead, we have to fill this gap by providing students with additional teaching materials. 
Table 1. Comparison between AR uses before and during COVID - 19 period

\begin{tabular}{|l|c|c|c|c|}
\hline & \multicolumn{2}{|c|}{ Face-to-face training } & \multicolumn{2}{c|}{ Online training (during COVID-19 period) } \\
\hline & Guidelines & Laboratory & Guidelines & $\begin{array}{c}\text { Training material } \\
\text { (photos, videos, text) }\end{array}$ \\
\hline Explanations & $\mathrm{x}$ & $\mathrm{x}$ & $\mathrm{x}$ & $\mathrm{x}$ \\
\hline Lab views & - & - & - & $\mathrm{x}$ \\
\hline Concrete measurements & - & - & - & $\mathrm{x}^{*}$ \\
\hline Inside view of equipment & - & $\mathrm{x}$ & $\mathrm{x}$ & $\mathrm{x}^{*}$ \\
\hline In-situ view of equipment & $\mathrm{x}$ & - & $\mathrm{x}$ & $\mathrm{x}^{*}$ \\
\hline Power plant views & $\mathrm{x}$ & - & - & $\mathrm{x}^{*}$ \\
\hline Web links & - & $\mathrm{x}$ & & ${ }^{*}$ \\
\hline
\end{tabular}

Note: *Additional training material to supplement information previously provided during face-to-face training

Table 1 synthesizes comparatively the necessary adjustments made for using AR in education, due to COVID-19. AR bridges the two sides, narrowing their gap and facilitating the real touch of reality.

Based on the existing results provided by AR implementation, three AR directions to overcome the barriers raised by COVID-19 are considered:

- to upgrade the augmentations with additional AR consisting in: detailed explanations, inside and in-situ views of equipment, power plant views;

- to provide augmentations with items that students can no longer see in face-to-face reality. To this end, special attention has to be given to providing students with sufficient videos and photos presenting the laboratory and its equipment (Fig. 7). One of the major drawbacks raised by the online engineering education is the impossibility to perform a proper real experiment involving equipment manoeuvres and measurements (Fig. 8). In this context, AR is one of the friendliest, effective and efficient tools used to overcome this deficiency.

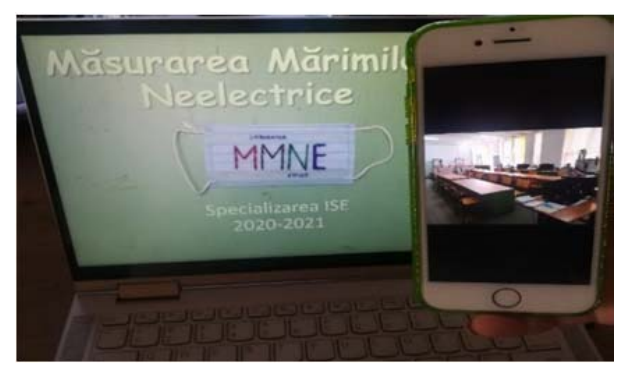

Figure 7. General view of a laboratory (of Nonelectrical Parameters Measurement)

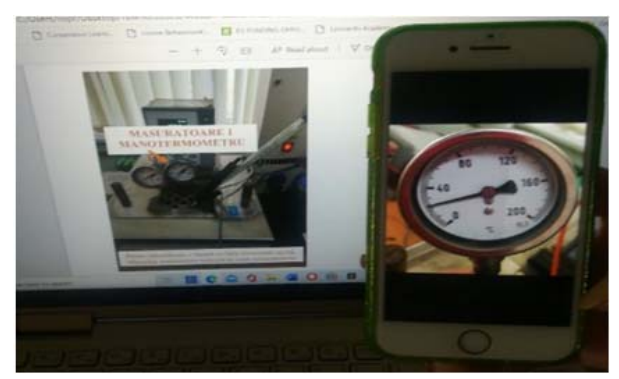

Figure 8. Measurement during experiment (temperature measurement on a gas pressure thermometer)
- to use augmentations in guidelines: explanations for the experiments, real in-situ views and web links to industrial manufacturing companies. For example, Fig. 9 shows a web link to the Switchgear for Secondary Distribution Systems [17]. These augmentations can be kept and used in the form they were used during face-to-face training.

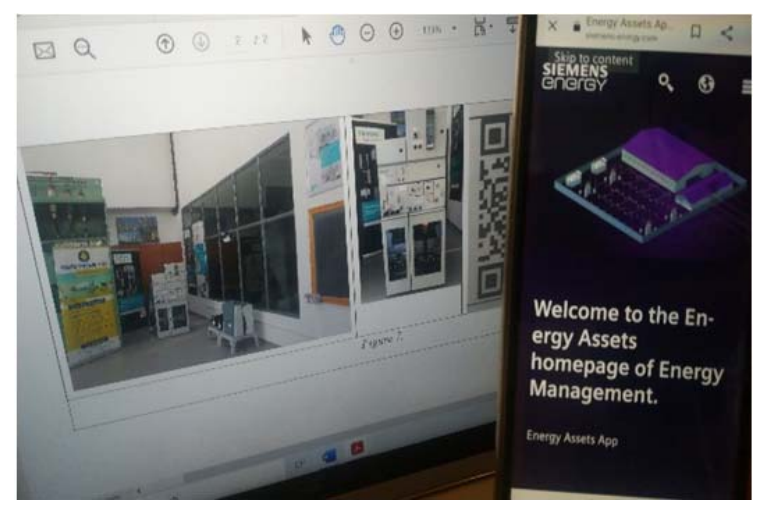

Figure 9. Example of a web link for (gas-insulated medium-voltage switchgear Type 8DJH).

\section{Conclusion}

The COVID-19 pandemic brought real challenges to face in engineering education. At the same time, it provided opportunities to adapt the way of interaction and education delivery.

The paper builds on previous work of implementing AR in experimental laboratories within the university, highlighting the usefulness of AR in power engineering education under the online teaching urged by COVID-19 pandemic restrictions.

To fill this gap determined by the COVID-19 pandemic, the paper proposes a possible way to enhance the use of $\mathrm{AR}$ in education and training. Several adjustments are introduced to overcome somehow the disadvantages of the exclusively online teaching that mainly prevents students to have real practical engineering experiences that can be gained in laboratories and power plants. 


\section{References}

[1]. Krishnamurthy, S. (2020). The future of business education: A commentary in the shadow of the Covid-19 pandemic. Journal of Business Research, 117, 1-5.

[2]. Dietrich, N., Kentheswaran, K., Ahmadi, A., Teychené, J., Bessière, Y., Alfenore, S., ... \& Sperandio, M. (2020). Attempts, successes, and failures of distance Learning in the time of COVID19. Journal of Chemical Education,97(9), 24482457.

[3]. Lee, S. M., \& Trimi, S. (2020). Convergence innovation in the digital age and in the COVID-19 pandemic crisis. Journal of Business Research, 123, 14-22.

[4]. Yin, J. H., Chng, C. B., Wong, P. M., Ho, N., Chua, M., \& Chui, C. K. (2020). VR and AR in human performance research-An NUS experience. Virtual Reality \& Intelligent Hardware, 2(5), 381-393.

[5]. Sepasgozar, S. M. (2020). Digital Twin and WebBased Virtual Gaming Technologies for Online Education: A Case of Construction Management and Engineering. Applied Sciences, 10(13), 4678.

[6]. Bacca, J., Baldiris, S., Fabregat, R., \& Graf, S. (2014). Augmented Reality Trends in Education: A Systematic Review of Research and Applications. Educational Technology \& Society, 17(4), 133-149.

[7]. Martín-Gutiérrez, J., Mora, C. E., Añorbe-Díaz, B., \& González-Marrero, A. (2017). Virtual technologies trends in education. EURASIA Journal of Mathematics, Science and Technology Education, 13(2), 469-486.

[8]. Cipresso, P., Giglioli, I. A. C., Raya, M. A., \& Riva, G. (2018). The past, present, and future of virtual and augmented reality research: a network and cluster analysis of the literature. Frontiers in psychology, 9, 2086.

[9]. Daineko, Y., Dmitriyev, V., \& Ipalakova, M. (2017). Using virtual laboratories in teaching natural sciences: An example of physics courses in university. Computer Applications in Engineering Education, 25(1), 39-47.
[10]. Müssig, J., Clark, A., Hoermann, S., Loporcaro, G., Loporcaro, C., \& Huber, T. (2020). Imparting Materials Science Knowledge in the Field of the Crystal Structure of Metals in Times of Online Teaching: A Novel Online Laboratory Teaching Concept with an Augmented Reality Application. Journal of Chemical Education, 97(9), 2643-2650.

[11]. Iwanaga, J., Loukas, M., Dumont, A. S., \& Tubbs, R. S. (2020). A review of anatomy education during and after the COVID-19 pandemic: Revisiting traditional and modern methods to achieve future innovation. Clinical Anatomy, 33(8).

[12]. Wright, R. (2016). Augmented Reality as experimental art practice: from information overlay to software assemblage. In Proceedings of the 22nd international symposium on electronic art ISEA2016. Hong Kong.

[13]. Elavarasan, R. M., \& Pugazhendhi, R. (2020). Restructured society and environment: A review on potential technological strategies to control the COVID-19 pandemic. Science of The Total Environment, 138858.

[14]. Opriş, I., Costinaş, S., Ionescu, C. S., \& Gogoaşe Nistoran, D. E. (2018). Step-by-step augmented reality in power engineering education. Computer Applications in Engineering Education, 26(5), 15901602.

[15]. Opriş, I., Costinaş, S., Ionescu, C. S., \& Nistoran, D. E. G. (2019, March). Experiencing Augmented Reality in Power Engineering Education. In 2019 11th International Symposium on Advanced Topics in Electrical Engineering (ATEE) (pp. 1-6). IEEE.

[16]. ABB (2020). UniGear Digital, The innovative solution for medium-voltage (MV) switchgear. Retrieved from: https://new.abb.com/mediumvoltage/switchgear/air-insulated/iec-and-otherstandards/unigear-digital [accessed: 15 June 2020].

[17]. Siemens (2017). Switchgear Type 8DJH for Secondary Distribution Systems up to $24 \mathrm{kV}$, GasInsulated, Catalog HA 40.2. Retrieved from: https://assets.new.siemens.com/siemens/assets/api/uu id:60f3dbd7588876438a66d3503921eedeadc95ad2/8 djhcompact-en-cataloge.pdf [accessed: 15 June 2020]. 